\title{
Influence of Putrescine Application on Storability, Postharvest Quality and Antioxidant Activity of Two Iranian Apricot (Prunus armeniaca L.) Cultivars
}

\author{
Gholamhossein DAVARYNEJAD*, Mehdi ZAREI, Elham \\ ARDAKANI, Mohamad Ebrahim NASRABADI \\ Department of Horticultural Science, Faculty of Agriculture, Ferdowsi University of Mashhad, P.O. \\ Box91775-1163, Mashhad, Iran; davarynej@um.ac.ir (*corresponding author)
}

\begin{abstract}
The limited postharvest storage life of apricot is the focus of this study. Presenting a solution to improve the postharvest storage of studied apricot cultivars is the goal. Studding the effect of different concentration of postharvest putrescine on quality attributes and antioxidant activity of two apricot cultivars during storage is the approach taken. The two apricot cultivars ('Lasgerdi' and 'Shahrodi') were harvested at the commercial ripening stage, and fruits were immerged in 1,2,3 and $4 \mathrm{mM}$ putrescine as well as distilled water (control) for $5 \mathrm{~min}$, then fruits were packed in boxes with polyethylene cover and stored at $4{ }^{\circ} \mathrm{C}$ and $95 \%$ relative humidity for 20 days. The changes in weight loss, fruit firmness, total soluble solids, titratable acidity, $\mathrm{pH}$, maturity index, ascorbic acid, total phenolics and antioxidant activity were estimated after 0, 5, 10, 15 and 20 days during storage. The results showed that the weight loss, total soluble solids, $\mathrm{pH}$ and maturity index increased significantly while the fruit firmness, titratable acidity, ascorbic acid, total phenolics and antioxidant activity decreased significantly during storage for both cultivars. During storage, a significant difference between control and putrescine treatments in all measured parameters is observed. The putrescine treatments reduced significantly the weight loss and maintained their firmness. In this condition, the highest and lowest of titratable acidity, ascorbic acid, total phenolics and antioxidant activity were observed in treatments of $4 \mathrm{mM}$ putrescine and control, respectively. The data revealed that the quality of apricot fruits was improved by the use of putrescine treatment due to its effect on delaying the ripening processes.
\end{abstract}

Keywords: ascorbic acid, attributes, shelf life, total phenolics.

\section{Introduction}

The modern fruit industry needs research promoting the commercial attributes of fruit quality. For Apricot (Prunus armeniaca L.) this is of a great importance since attributes are too frequently not satisfactory to the customers (Davarynejad et al., 2010). Due to its nutritional and antioxidant properties, considerable attention has been paid to it in recent years. Apricot is known to contain considerable of vitamins (A and C), minerals, fibre, carotenoids, flavonoids, lycopene and other antioxidant compounds (Haciseferogullari et al., 2007; Munzuroglu et al., 2003).

Apricot is climacteric fruit with a limited postharvest storage life due to acceleration of quality loss, affecting some properties such as fruit firmness, texture, total soluble solids and titratable acidity. A suitable method for shelf life extension, which avoids detrimental effects on quality of fruit, would be beneficial for both the consumer and the producer. A number of strategies have been used to improve the quality properties and shelf life of apricot fruit, such as low temperature storage and postharvest treatments with polyamines (Martínez-Romero et al., 2002), aminoethoxyvinylglycine (AVG) and 1-methylcyclopropene (1-MCP) (Palou and Crisosto, 2003).
Polyamines (PAs) are known as a group of natural compounds with aliphatic nitrogen structure that are ubiquitous in plants, animals and microorganisms. The major polyamines are found in every plant cell, such as spermidine (Spd) and spermine (Spm) and putresine (Put) (Galston and Sawhney, 1990). It is known that polyamines play important roles in many physiological processes in plants, including growth and development of cell and respond to environmental stresses. Treatment with exogenous polyamines has been reported to increase fruit firmness in apples (Kramer et al., 1989, 1991; Wang et al., 1993), strawberry (Ponappa et al., 1993), tomato (Law et al., 1991), lemon (Valero et al., 1998 a, 1998b, 1998c ), peach (Bregoli et al., 2002) and plum (Serrano et al., 2003). Other beneficial effects of exogenous polyamines have been reported for both climacteric and non-climacteric fruit such as delayed colour changes, reduced mechanical damage and susceptibility to chilling injury and increased shelf life (Martinez-Romero et al., 2002; Perez-Vicente et al., 2002; Serrano et al., 1996). Thus polyamines treatment has the potential for commercial control of quality properties and increased shelf life of harvested fruit.

However, little information exists on the use of different concentration of putrescine to preserve apricot fruit quality during storage. Therefore, the objective of this re- 
search was to analyse and compare the effect of different concentrations of postharvest putrescine application on quality properties and antioxidant activity of two most important local and famous apricot cultivars ('Lasgerdi' and 'Shahrodi') during storage.

\section{Materials and methods}

The 'Lasgerdi' and 'Shahrodi' apricot cultivars harvested manually at commercial maturity stage at July 2011 from 14 years-old trees in Mashhad, Iran. The average temperature, the amount of rainfall and relative humidity in growing season (March to July) of 2011 were $28.6^{\circ} \mathrm{C}, 20$ $\mathrm{mm}$ and $26 \%$, respectively. Soil texture were being sandloam, $\mathrm{EC}=4.1\left(\mathrm{ds} . \mathrm{m}^{-1}\right)$ and soil $\mathrm{pH}=7.2$. The trees were spaced 6 and $3 \mathrm{~m}$ between and along the rows, respectively. Trees were grown under traditional irrigation and routine cultural practices suitable for commercial fruit production.

Fruits were transported by a ventilated car to the laboratory soon after harvest, where apricots with defects (sunburns, cracks, cuts and bruises in peel) were discarded and then fruits were selected in accordance with their colour and weight. The homogeneous fruits were randomized and divided into 5 lots of 80 fruit for following treatments in 4 replicates (each replicate contained 20 individual fruit): control (distilled water) and different concentration of putrescine (1,2,3 and $4 \mathrm{mM})$. Treatments were performed by dipping fruits in $10 \mathrm{~L}$ of solution for $5 \mathrm{~min}$, and then they were left to dry at room temperature and were packed in boxes with polyethylene cover and after stored at $4^{\circ} \mathrm{C}$ and $95 \%$ relative humidity (RH) for 20 days. After $0,5,10,15$ and 20 days ( 5 days intervals), 3 fruit from each replicate for each treatment (12 fruit) were sampled for analytical determinations. All reagents, solvents and standards were of analytical reagent grade.

\section{Weight loss and firmness of fruit}

The same samples were evaluated for weight loss of the fruit each time at 5 day intervals until the end of experiment. Fruits were weighted in the air on a balance of accuracy of $0.001 \mathrm{~g}$. The weight loss was determined by the following formula: weight loss $(\%)=[(\mathrm{A}-\mathrm{B}) / \mathrm{A}] \times 100$. Where $A$ indicates the fruit weight at the time of harvest and $\mathrm{B}$ indicates the fruit weight after storage intervals. Fruit firmness was determined by a fruit pressure tester (8 $\mathrm{mm}$ diameter probe) on pared surfaces from opposite sides of each fruit and the results were expressed as Newtons $(\mathrm{N})$.

\section{Total soluble solids, titratable acidity, $\mathrm{pH}$ and maturity} index

The total soluble solids (TSS) were determined with a digital refractrometer (Erma, Tokyo, calibrated using distilled water). Results were reported as degree ${ }^{\circ} \mathrm{Brix}$ at $21^{\circ} \mathrm{C}$. The titratable acidity (TA) was determined by us- ing a digital acidity assay and expressed as $\mathrm{g}$ of malic acid per $100 \mathrm{~g}$ of fresh weight $(\mathrm{g} / 100 \mathrm{~g}$ FW). The $\mathrm{pH}$ measurements were performed using a digital $\mathrm{pH}$ meter (Metrohm 601 ) at $21^{\circ} \mathrm{C}$. Maturity index was calculated by dividing total soluble solids to titratable acidity.

\section{Ascorbic acid and total phenolics}

Ascorbic acid was determined by employing the method described by Mazumdar and Magumdar (2003). Results were expressed as mg ascorbic acid per $100 \mathrm{~g}$ of fresh weight $(\mathrm{mg} / 100 \mathrm{~g} \mathrm{FW})$. The total phenolics were determined by using Folin-Ciocalteu method (Singleton et al., 1999). One gram of apricot tissue was extracted with 10 $\mathrm{ml}$ methanol (85\%). $250 \mu \mathrm{l}$ of this extract was dissolved in a $250 \mu \mathrm{l}$ of sterile distilled water, and then samples were mixed with $2.5 \mathrm{ml}$ of 10-fold-diluted Folin-Ciocalteu reagent and $2 \mathrm{ml}$ of $7.5 \%$ sodium carbonate. The mixture was shaked for 1.5 to 2 hours before the absorbance was measured by a Cecil 2010 UV-visible spectrophotometer at $765 \mathrm{~nm}$. Gallic acid was used as a standard. The results were expressed as $\mathrm{mg}$ gallic acid equivalent in $100 \mathrm{~g}$ fresh weight (mg/GAE $100 \mathrm{~g} \mathrm{FW).}$

\section{Antioxidant activity}

Antioxidant activity was assessed according to the method of Ismail et al. (2009). Briefly, $1 \mathrm{~g}$ of apricot tissue was extracted with $10 \mathrm{ml}$ methanol (85\%). One $\mathrm{ml}$ of this extracts were mixed with $2 \mathrm{ml}$ of $0.15 \mathrm{mM} \mathrm{DPPH}$ in methanol. The mixtures were shaken vigorously and left to stand for $30 \mathrm{~min}$ (under dark condition). The control was prepared by adding $2 \mathrm{ml}$ of DPPH to $1 \mathrm{ml}$ methanol. $\mathrm{Ab}$ sorbance of the resulting solution was measured at $517 \mathrm{~nm}$ by a Cecil 2010 UV-visible spectrophotometer. The antioxidant activity is expressed in the form of the percentage of free radical scavenging.

\section{Statistical analysis}

This experiment was conducted according to factorial based on completely randomized block design with 4 replications. Data were analyzed by Statistical Analysis System (SAS) software Version 9.1 using analysis of variance (ANOVA) and differences among means were determined for significance at $p<0.05$ using Tukey's test.

\section{Results and discussion}

\section{Weight loss}

The weight loss increased significantly during storage at $4^{\circ} \mathrm{C}$ in both cultivars (Fig. 1). Similar results were also reported by Ghasemnezhad et al. (2010). There were a significant difference $(p<0.05)$ between treatments of control and putrescine in terms of their effects on weight loss (Fig. 1). The control treatment had the highest weight loss during storage, followed by the $1 \mathrm{mM}$ putrescine treatment, while the lowest was in $4 \mathrm{mM}$ putrescine treatment. The results were in agreement with the findings re- 
214

ported by Martinez-Romero et al. (2002) and Serrano et al. (2003).

According to Woods (1990), weight loss in fruit during storage could be due to the water exchange between the internal and external atmosphere, the transpiration rate being accelerated by cellular breakdown. In this sense, the putrescine treatment modified or consolidated the cell disposition and delays the removal of epicuticular waxes which play an important role in water exchange through the skin, and then lower weight loss would occur. With regard to the results, the putrescine treatments showed significantly less of weight loss during storage being a negative correlation between putrescine concentrations and weight loss.

\section{Fruit firmness}

As shown in Fig. 2, fruit firmness (expressed as forcedeformation ratio) declined rapidly during storage at $4^{\circ} \mathrm{C}$ for both cultivars, that the fruit firmness levels at the initial of the storage period were higher than the end ones just for the all treatments. Martínez-Romero et al. (2002) has reported that apricot fruit firmness decreased significantly during storage. Significant differences $(p<0.05)$ were revealed among the treatments for fruit firmness (Fig. 2). The treatment of putrescine showed significantly highest

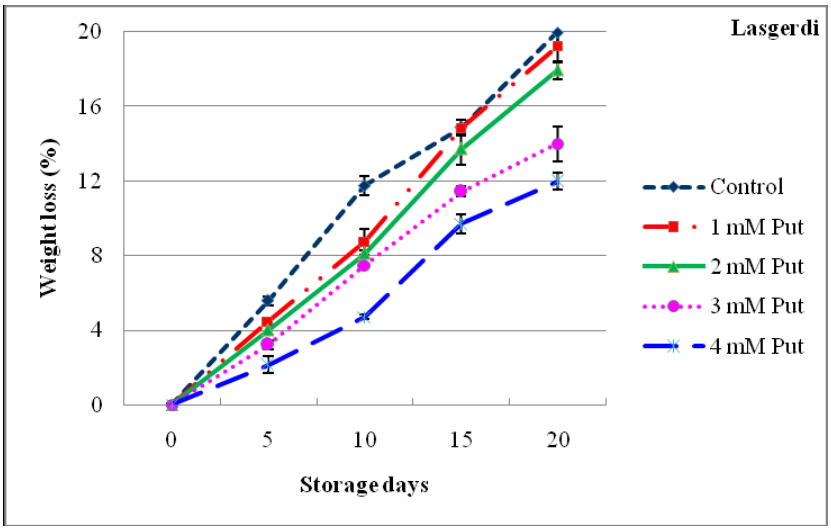

firmness levels than control treatment during storage. The higher the putrescine concentration applied, the greater the improvement in firmness, that highest firmness values were observed in $4 \mathrm{mM}$ putrescine treatment. Similar results were also reported for apples (Wang et al., 1993), other apricot cultivars (Martínez-Romero et al., 2002), plum (Serrano et al., 2003) and strawberry (Zokaee et al., 2007).

Fruit softening during storage is the main factor limiting storage and shelf life of apricot fruit. The effect of polyamines on the reduction of fruit softening or firmness augmentation can be attributed to their capacity cross-link to pectic substances in the cell wall, resulting in rigidification that is detectable immediately after treatment (Abbot et al., 1989) and also as inhibition of the action of walldegrading enzymes, such as pectinesterase, pectinmethylesterase and polygalacturonase and reduce fruit softening during storage (Valero et al., 2002). In accordance with this hypothesis, the putrescine exogenously applied went to cell walls to maintain high levels of fruit firmness and these high levels of firmness lead to increased shelf life.

\section{Total soluble solids}

For both cultivars, content of total soluble solids decreased during the first 5 days of storage and from this time

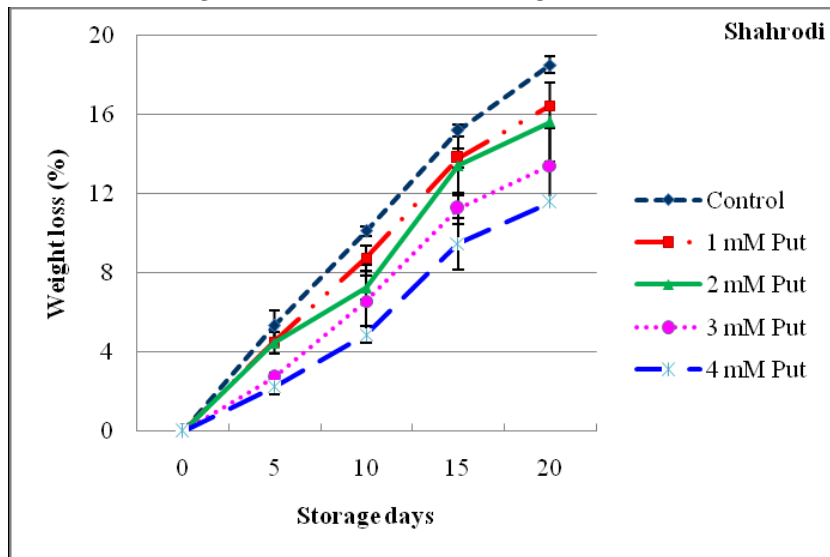

Fig. 1. Effect of putrescine on weight loss (\%) of two Iranian apricot cultivars during storage at $4^{\circ} \mathrm{C}$. The results represent the means of 12 fruit in 4 replicates \pm standard errors
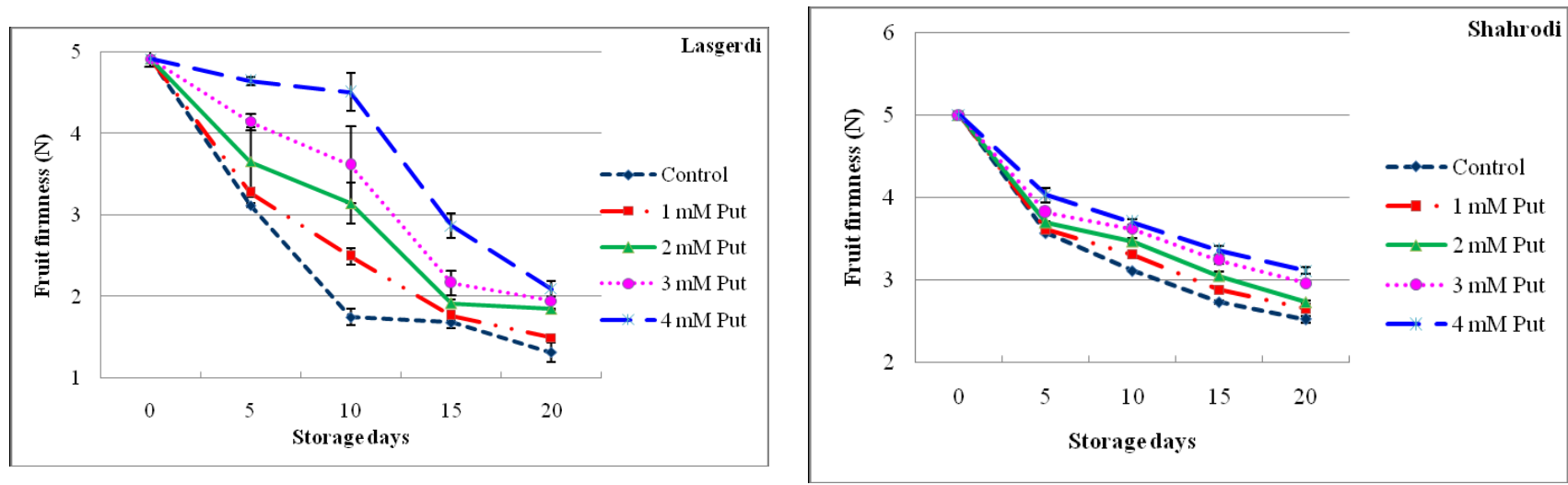

Fig. 2. Effect of putrescine on fruit firmness $(\mathrm{N})$ of two Iranian apricot cultivars during storage at $4^{\circ} \mathrm{C}$. The results represent the means of 12 fruit in 4 replicates \pm standard errors 
until end of the storage period increased (Fig. 3). Similar patterns of changes were reported by Zokaee and EsnaAshari (2008). As shown in Fig. 3, a variation in terms of total soluble solids content was observed among the treatments and the differences were statistically significant $(p<$ $0.05)$. The highest concentration of total soluble solids was observed for control treatment during storage, followed by $1 \mathrm{mM}$ and $2 \mathrm{mM}$ putrescine treatments while the lowest was in $4 \mathrm{mM}$ putrescine treatment. Similar data were also reported for apricot (cv. 'Tokhm Sephid') and peach (cv. 'Zapherani') (Zokaee and Esna-Ashari, 2008).

The during storage, increase in content of total soluble solids was probably due to concentrated juice content as a result of dehydration and hydrolysis of polysaccharides. During storage, all treatments showed increases in content of total soluble solids, although the increases were significantly lower in treatment of putrescine than in control treatment. This effect of putrescine can be attributed to low levels of the respiration rate, ethylene production and delay in ripening process. According to data, one can say that there is an inversely relation between putrescine concentrations and level of total soluble solids during storage.

\section{Titratable acidity}

The results showed that titratable acidity content decreased significantly during storage at $4^{\circ} \mathrm{C}$ for both culti-

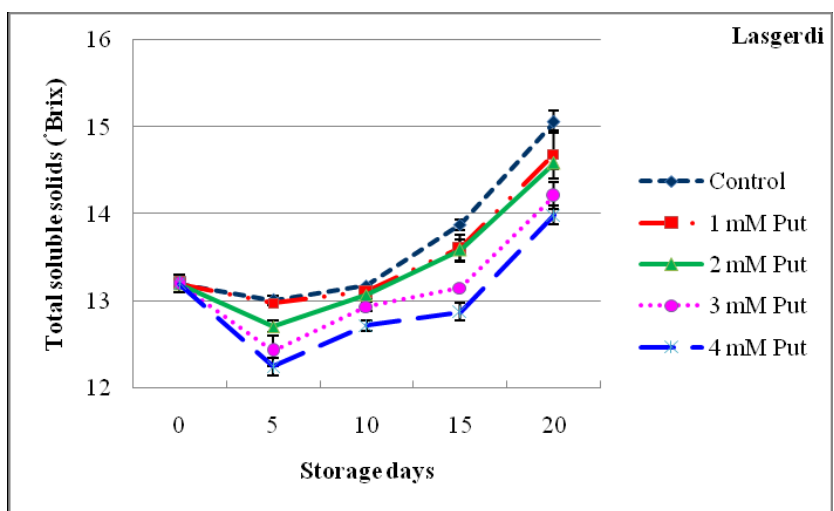

vars (Fig. 4), which is in agreement with results Ghasemnezhad et al. (2010). There was a significant difference $(p<0.05)$ between control and putrescine treatments in terms of their effects on level of titratable acidity (Fig. 4). Among the studied treatments, $4 \mathrm{mM}$ putrescine treatments had the highest amount of titratable acidity and control treatment had the lowest titratable acidity content during storage. Zokaee et al. (2007) also reported that the treated strawberry fruits with putrescine had the highest amount of titratable acidity during storage.

The titratable acidity is an important factor in maintaining the quality of apricot fruits, which is directly related to the organic acids content present in the fruit. The putrescine treatment showed decreases were significantly lower in content of titratable acidity than control treatment during storage. Zokaee et al. (2007) and Ishaq et al. (2009) suggested that titratable acidity decreases could be due to consumption of organic acids in fruits during respiration. In the present study it seems that putrescine treatments did have any significant effect on respiration process which could reduction or delay of respiration and maintain titratable acidity.

\section{pH}

As shown in Fig. 5 , $\mathrm{pH}$ values decreased during the first 5 days of storage and from this time until end of the storage

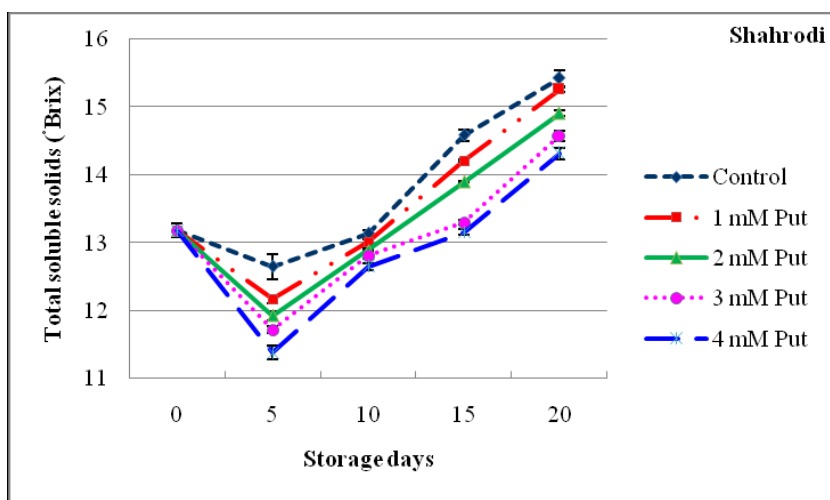

Fig. 3. Effect of putrescine on total soluble solids ( ${ }^{\circ}$ Brix) of two Iranian apricot cultivars during storage at $4{ }^{\circ} \mathrm{C}$. The results represent the means of 12 fruit in 4 replicates \pm standard errors
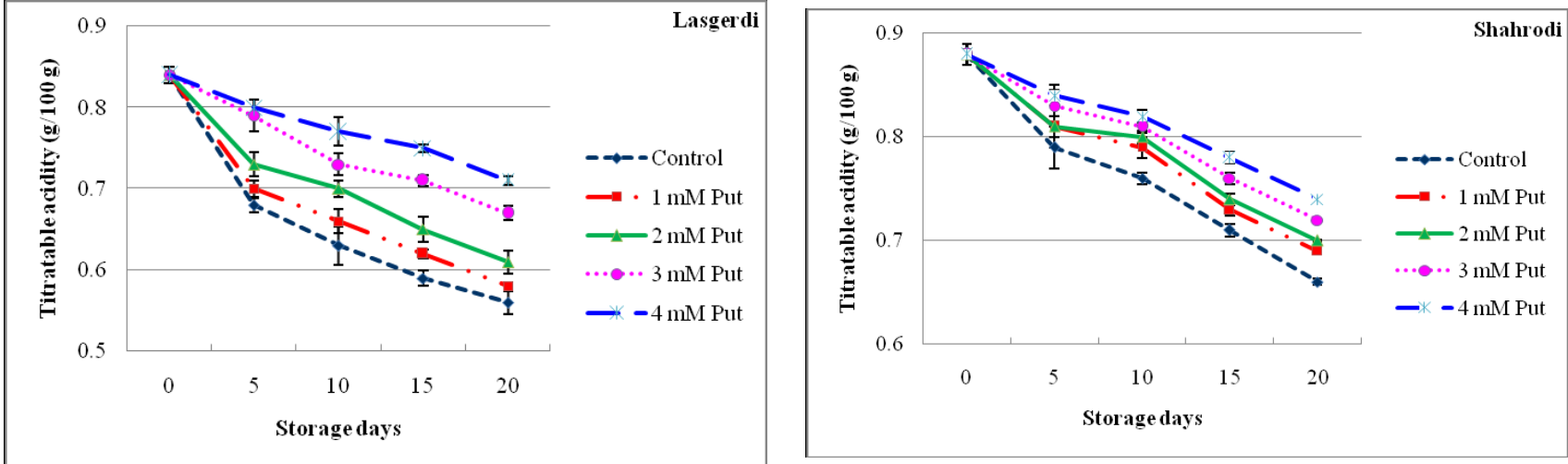

Fig. 4. Effect of putrescine on titratable acidity $\left(\mathrm{g} / 100 \mathrm{~g}\right.$ fresh weight) of two Iranian apricot cultivars during storage at $4^{\circ} \mathrm{C}$. The results represent the means of 12 fruit in 4 replicates \pm standard errors 
216

period increased for both cultivars. Significant differences $(p<0.05)$ were revealed among the different treatments for $\mathrm{pH}$ values (Fig. 5). The highest and lowest the $\mathrm{pH}$ values were observed in control and $4 \mathrm{mM}$ putrescine treatments, respectively. Our results were in agreement with data reported by Zokaee and Esna-Ashari (2008).

The all treated fruits showed increases in $\mathrm{pH}$ values, although the increases were significantly lower in treated fruits with putrescine than in control fruit during storage. This effect of putrescine might be due to create a thin layer on the surface of fruit which delayed degradation process. With respect to titratable acidity and $\mathrm{pH}$ values, titratable acidity content significantly decreased while $\mathrm{pH}$ value significantly increased during storage for both cultivars. Thus, one can say that there is an inversely relation between titratable acidity and $\mathrm{pH}$.

\section{Maturity index}

In both cultivars, the maturity index increased significantly during storage at $4^{\circ} \mathrm{C}$, that the maturity index levels at the initial of the storage period were higher than the end ones just for the all treatments (Fig. 6). There were significant differences in the maturity index content of the different treatments, that control treatments had the highest amount of maturity index than the other treatments (Fig. 6). Similar results were also reported for plum (cv. 'Angelino') (Khan et al., 2008).

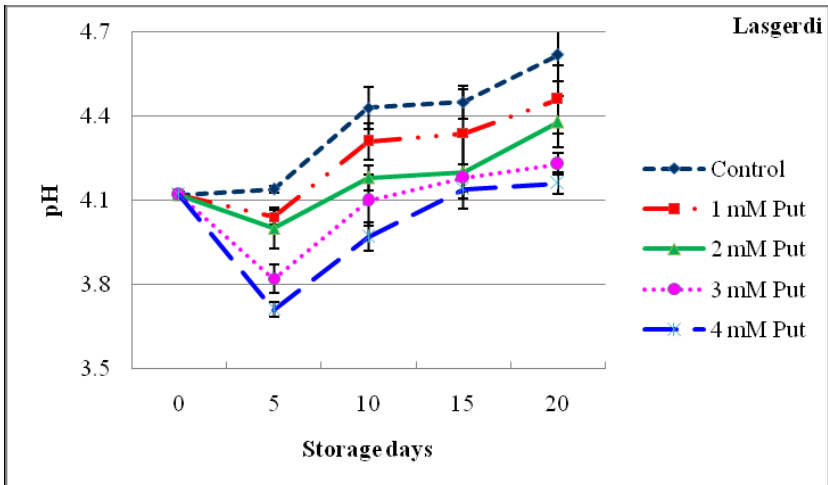

The maturity index (TSS/TA) is responsible for the taste and flavor of apricot. Khan et al. (2008) reported that the lower maturity index in putrescine treatment is might be due to their higher titratable acidity, as compared to control treatment, that is in agreement with our results.

\section{Ascorbic acid}

The content of ascorbic acid decreased significantly during storage at $4^{\circ} \mathrm{C}$ for both cultivars (Fig. 7). Ishaq et al. (2009) reported also the ascorbic acid content in apricot fruit was reduced during storage. As shown in Fig. 7, a significant variation in ascorbic acid concentration was found among the studied treatments. The lowest concentration of ascorbic acid was observed for control treatment during storage, followed by $1 \mathrm{mM}$ and $2 \mathrm{mM}$ putrescine treatments while the highest was in $4 \mathrm{mM}$ putrescine treatment.

Ascorbic acid is an important nutrient quality factors, which is very sensitive to degradation due to its oxidation compared to other nutrients during storage. The all treatments showed decreases in content of ascorbic acid, although the decreases were significantly lower in treatment of putrescine than in control treatment during storage. Ishaq et al. (2009) reported that the content of ascorbic acid decreases during storage could be due to the conversion of dehydroascobic to diketogulonic acid by oxidation. The effect of putrescine may be ascribed to decreased or delayed ascorbate oxidase activity.

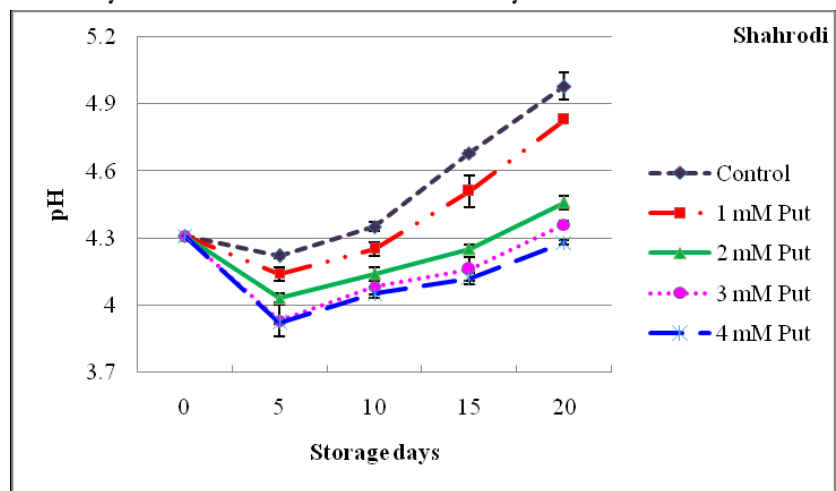

Fig. 5. Effect of putrescine on $\mathrm{pH}$ of two Iranian apricot cultivars during storage at $4{ }^{\circ} \mathrm{C}$. The results represent the means of 12 fruit in 4 replicates \pm standard errors
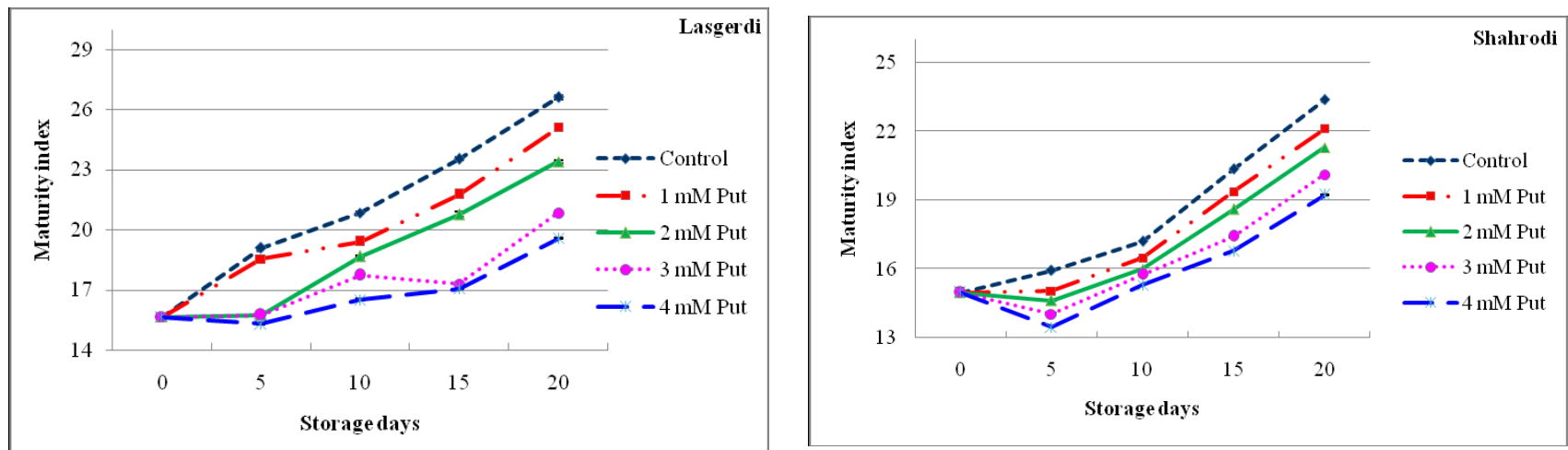

Fig. 6. Effect of putrescine on maturity index (TSS/TA) of two Iranian apricot cultivars during storage at $4^{\circ} \mathrm{C}$. The results represent the means of 12 fruit in 4 replicates \pm standard errors 

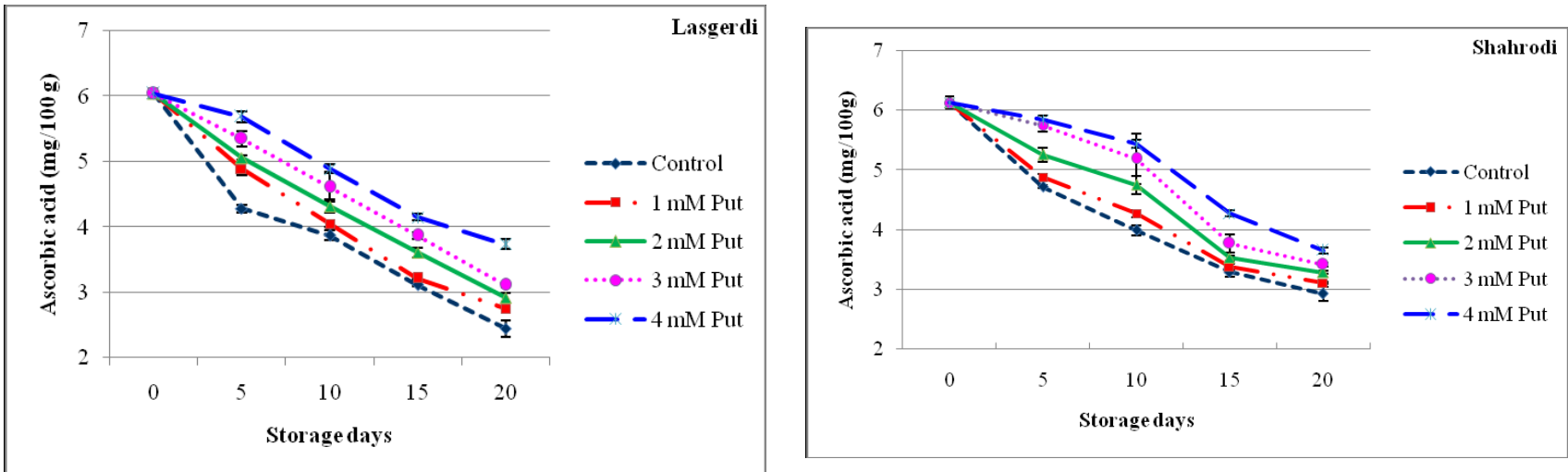

Fig. 7. Effect of putrescine on ascorbic acid (g/100 g fresh weight) of two Iranian apricot cultivars during storage at $4^{\circ} \mathrm{C}$. The results represent the means of 12 fruit in 4 replicates \pm standard errors

\section{Totalphenolics}

For both cultivars, total phenolics content decreased significantly during storage at $4^{\circ} \mathrm{C}$, that the total phenolics levels at the initial of the storage period were higher than the end ones just for the all treatments (Fig. 8). As shown in Fig. 8, a variation in terms of total phenolics content was observed among the treatments and the differences were statistically significant $(p<0.05)$. The maximum concentration of total phenolics was observed for $4 \mathrm{mM}$ putrescine treatment during storage, followed by $3 \mathrm{mM}$ and $2 \mathrm{mM}$ putrescine treatments while the highest was in control treatment.

According to data, all treatments showed decreases in content of total phenolics, although the decreases were significantly lower in treatment of putrescine than in control treatment. During storage, level of total phenolics decrease might be due to breakdown of cell structure in order to senescence phenomena (Ghasemnezhad et al., 2010). It was assumed that the effect of putrescine treatment on maintain of total phenolics content can be attributed to delay in senescence process.

\section{Antioxidant Activity}

The data indicated that the antioxidant activity decreased significantly during storage at $4^{\circ} \mathrm{C}$ for both cultivars (Fig. 9). There was a significant difference $(p<0.05)$

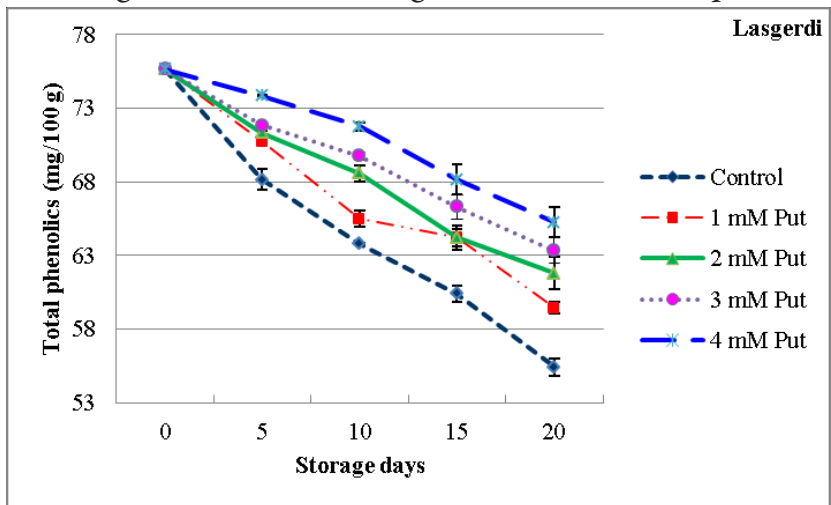

between control and putrescine treatments in terms of their effects on level of antioxidant activity (Fig. 9). During storage, treatments of $4 \mathrm{mM}$ putrescine had the highest antioxidant activity and control treatment had the lowest antioxidant activity.

The determination of antioxidant activity is one of the ways of expressing the nutritional and biological value of fruits. The results showed that the antioxidant activity decline along with deceases of total phenolic and ascorbic acid contents. Thus, it can be concluded that antioxidant activity is closely correlated with the total phenolics and ascorbic acid content. In previous researches, the positive correlation between antioxidant activity and total phenolics has been reported (Díaz-Mula et al., 2009; Ghasemnezhad et al., 2010). The treatment of putrescine maintained antioxidant activity of the fruit significantly during storage being a positive correlation between putrescine concentrations and antioxidant activity of fruit. This effect of putrescine treatment was probably due to maintain of total phenolics and ascorbic acid levels during storage.

\section{Conclusion}

Apricot is a climacteric fruit with limited postharvest storage life due to acceleration of quality loss. A suitable method for shelf life extension, which avoids detrimental

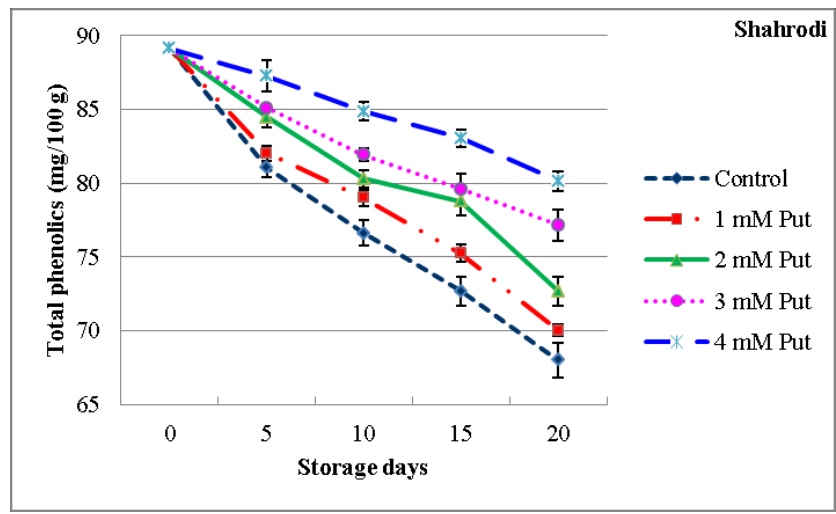

Fig. 8. Effect of putrescine on total phenolics $\left(\mathrm{g} / 100 \mathrm{~g}\right.$ fresh weight) of two Iranian apricot cultivars during storage at $4^{\circ} \mathrm{C}$. The results represent the means of 12 fruit in 4 replicates \pm standard errors 

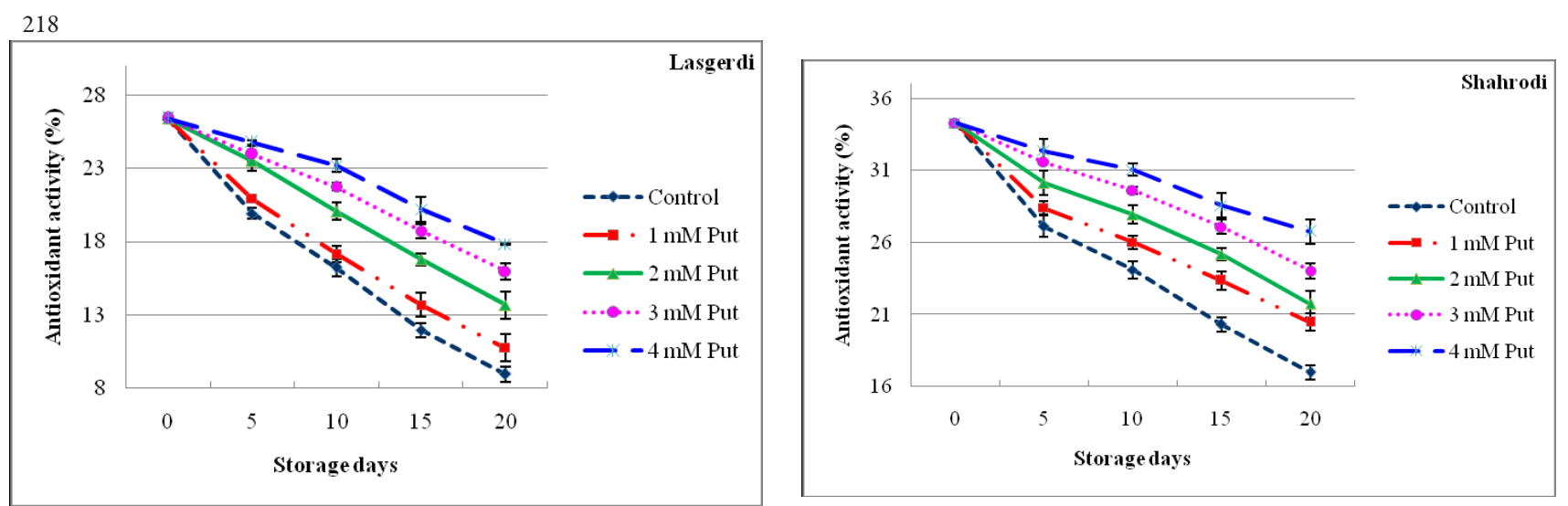

Fig. 9. Effect of putrescine on antioxidant activity (\%) of two Iranian apricot cultivars during storage at $4^{\circ} \mathrm{C}$. The results represent the means of 12 fruit in 4 replicates \pm standard error

effects on quality of fruit, would be beneficial for both the consumer and the producer. In this study, effect of different concentration of postharvest putrescine application on quality properties and antioxidant activity of two most important Iranian apricot cultivars ('Lasgerdi' and 'Shahrodi') during storage were investigated. This research showed the same behaviour in all measured factors during storage at $4^{\circ} \mathrm{C}$ for both cultivars apricot. The weight loss, total soluble solids, $\mathrm{pH}$ and maturity index increased significantly while the fruit firmness, titratable acidity, ascorbic acid, total phenolics and antioxidant activity decreased significantly during storage for both cultivars. In addition, statistically significant differences were observed between control and putrescine treatments in all measured parameters during storage. Exogenous putrescine treatments have shown improvement of apricot during storage at $4^{\circ} \mathrm{C}$. Thus, the results suggest that putrescine treatment may be used commercially to extend the storage life of apricot.

\section{Acknowledgements}

The authors would like to acknowledge from Ferdowsi University of Mashhad for its kind cooperation and their assistance in different aspects of this study.

\section{References}

Abbott JA, Conway WS, Sams CE (1989). Postharvest calcium chloride infiltration affects textural attributes of apples. J Am Soc Hort Sci 114(6):932-936.

Bregoli AM, Scaramagli S, Costa G, Sabatini E, Ziosi V, Biondi S, Torrigiani P (2002). Peach (Prunus persica L.) fruit ripening: aminoethoxyvinylglycine (AVG) and exogenous polyamines affect ethylene emission and flesh firmness. Physiol Plant 114:472-481.

Davarynejad GH, Vatandoost S, Nyéki J, Szabó Z, Nagy PT (2010). Hazardous element content and consumption risk of 9 apricot cultivars. Inter J Hort Sci 16(4):61-65.

Díaz-Mula HM, Zapata PJ, Guillén F, Martínez-Romero D, Castillo S, Serrano M, Valero D (2009). Changes in hydrophilic and lipophilic antioxidant activity and related bioactive compounds during postharvest storage of yellow and purple plum cultivars. Postharvest Biol Technol 51:354-363.

Galston AW, Sawhney RK (1990). Polyamines in plant physiology. Plant Physiol 94:606-610.

Ghasemnezhad M, Shiri MA, Sanavi M (2010). Effect of chitosan coatings on some quality indices of apricot (Prunus armeniaca L.) during cold storage. Caspian J Env Sci 8(1):2533.

Haciseferogullari H, Gezer I, Ozcan MM, Asma BM (2007). Postharvest chemical and physical-mechanical properties of some apricot varieties cultivated in Turkey. J Food Eng 79:364-373.

Ishaq S, Rathore HA, Majeed S, Awan S, Zulfiqar-Ali-Shah S (2009). The Studies on the physico-chemical and organoleptic characteristics of apricot (Prunus armeniaca L.) produced in Rawalakot, Azad Jammu and Kashmir during storage. Pakistan J Nutr 8(6):856-860.

Ismail HK, Mehmet A, Hacer C (2009). Antioxidant capacity, total phenolics and some chemical properties of semimatured apricot cultivars grown in Malatya, Turkey. World Appl Sci J 6(4):519-523.

Khan AS, Singh Z, Abbasi NA (2007). Pre-storage putrescine application suppresses ethylene biosynthesis and retards fruit softening during low temperature storage in 'Angelino' plum. Postharvest Biol Technol 46:36-46.

Khan AS, Singh Z, Abbasi NA, Swinny EE (2008). Pre- or postharvest applications of putrescine and low temperature storage affect fruit ripening and quality of 'Angelino' plum. J Sci Food Agric 88:1686-1695.

Kramer GF, Wang CY, Conway WS (1989). Correlation of reduced softening and increased polyamine levels during low-oxygen storage of 'McIntosh' apples. J Am Soc Hort Sci 114:942-947.

Kramer GF, Wang CY, Conway WS (1991). Inhibition of softening by polyamine application in 'Golden Delicious' and 'McIntosh' apples. J Am Soc Hort Sci 116:813-819.

Law DM, Davies PJ, Mutschler MA (1991). Polyamine-induced prolongation of storage in tomato fruits. Plant Growth Regul 10:283-290. 
Martinez-Romero D, Serrano M, Carbonell A, Burgos L, Riquelme F, Valero D (2002). Effects of postharvest putrescine treatment on extending shelf life and reducing mechanical damage in apricot. J Food Sci 67(5):1706-1712.

Mazumdar BC, Magumdar K (2003). Methods on pysicochemical analysis of fruits. Daya Publishing House. Delhi-110035.

Munzuroglu O, Karatas F, Geckil H (2003). The vitamin and selenium contents of apricot fruit of different varieties cultivated in different geographical regions. Food Chem 83:205212.

Palou LH, Crisosto HC (2003). Postharvest treatments to reduce the harmful effects of ethylene on apricots. Acta Hort 599:31-38.

Perez-Vicente A, Martinez-Romero D, Carbonell A, Serrano M, Riquelme F, Guillen F (2002). Role of polyamines in extending shelf life and the reduction of mechanical damage during plum (Prunus salicina Lindl.) storage. Postharvest Biol Technol 25:25-32.

Ponappa T, Scheerens JC, Miller AR (1993). Vacuum infiltration of polyamines increases firmness of strawberry slices under various storage conditions. J Food Sci 58(2):361-364.

Serrano M, Martínez-Madrid MC, Martínez G, Riquelme F, Petrel MT, Romojaro F (1996). Review: role of polyamines in chilling injury of fruit and vegetables. Food Sci Technol Int 2:195-199.

Serrano M, Martinez-Romero D, Guillen F, Valero D (2003). Effects of exogenous putrescine on improving shelf life of four plum cultivar. Postharvest Biol Technol 30:259-271.

Singleton VL, Orthofer R, Lamuela-Raventós RS (1999). Analysis of total phenols and other oxidation substrates and antioxidants by means of folin-ciocalteau reagent. Methods Enzymol 299:152-178.
Valero D, Martinez-Romero D, Riquelme F (1998a). Polyamine response to external mechanical bruising in two mandarin cultivars. Hort Sci 33(7):1220-1223.

Valero D, Martinez-Romero D, Serrano M, Riquelme F (1998b). Postharvest gibberellin and heat treatment effects on polyamines, abscisic acid and firmness in lemons. J Food Sci 63(4):611-615.

Valero D, Martinez-Romero D, Serrano M, Riquelme F (1998c). Influence of postharvest treatment with putrescine and calcium on endogenous polyamines, firmness, and abscisic acid in lemon (Citrus lemon L. Burm cv. Verna). J Agric Food Chem 46:2102-2109.

Valero D, Perez-Vicente A, Martinez-Romero D, Castillo S, Guillen F, Serrano M (2002). Plum storability improved after calcium and heat postharvest treatments: role of polyamines. J Food Sci 67(7):2571-2575.

Wang CY, Conway WS, Abbott JA, Kramer GF, Sams CE (1993). Postharvest infiltration of polyamines and calcium influences ethylene production and texture changes in 'Golden Delicious' apples. J Am Soc Hort Sci 118:801-806.

Woods JL (1990). Moisture loss from fruits and vegetables. Postharvest News Inform 1:195-199.

Zokaee-Khosroshahi MR, Esna-Ashari M, Ershadi A (2007). Effect of exogenous putrescine on post-harvest life of strawberry (Fragaria ananassa Duch.) fruit, cultivar 'Selva'. Sci Horti 114:27-32.

Zokaee-Khosroshahi MR, Esna-Ashari M (2008). Effect of putrescine application on post-harvest life and physiology of strawberry, apricot, peach and sweet cherry fruits. J Sci Technol Agric Natur Resour 12(45):219-230. 